\title{
A Feasibility Study of Capecitabine and Oxaliplatin for Patients with Stage II/III Colon Cancer -ACTOR Study-
}

\author{
MITSUKUNI SUENAGA ${ }^{1}$, TAKASHI AKIYOSHI ${ }^{2}$, EIJI SHINOZAKI ${ }^{1}$, YOSHIYA FUJIMOTO ${ }^{2}$, \\ SATOSHI MATSUSAKA ${ }^{1}$, TSUYOSHI KONISHI ${ }^{2}$, SATOSHI NAGAYAMA ${ }^{2}$, \\ YOSUKE FUKUNAGA ${ }^{2}$, KAZUYOSHI KAWAKAMI ${ }^{3}$, TAKASHI YOKOKAWA ${ }^{3}$, \\ TAKAHITO SUGISAKI ${ }^{3}$, MASASHI UENO $^{2}$ and TOSHIHARU YAMAGUCHI ${ }^{2}$ \\ ${ }^{1}$ Department of Gastroenterology, Cancer Institute Hospital, \\ Japanese Foundation for Cancer Research, Tokyo, Japan; \\ ${ }^{2}$ Department of Gastroenterological Surgery, Cancer Institute Hospital, \\ Japanese Foundation for Cancer Research, Tokyo, Japan; \\ ${ }^{3}$ Department of Pharmacy, Cancer Institute Hospital, Japanese Foundation for Cancer Research, Tokyo, Japan
}

\begin{abstract}
Background/Aim: Past studies have suggested that adjuvant capecitabine and oxaliplatin (CAPOX) provides decreased tumor relapse and longer survival in patients with curatively resected colon cancer. We report the first evidence of the feasibility of adjuvant CAPOX in Japanese patients with early colon cancer. Patients and Methods: Eligible patients had histologically-confirmed stage II/III colon cancer and received curative resection. The primary endpoint was completion rate of treatment after 8 cycles of adjuvant CAPOX. Results: Thirty-six patients were enrolled in this study. The completion rate of CAPOX and oxaliplatin were $77.8 \%$ and $61.1 \%$, respectively. The incidence of grade $\geq 3$ adverse events was neutropenia $(n=6)$, thrombocytopenia $(n=3)$, nausea $(n=5)$, hand-foot syndrome $(n=1)$ and peripheral sensory neuropathy $(n=1)$. Three-year disease-free survival for stage II patients and stage III patients were $100 \%$ and $79.3 \%$, respectively. Conclusion: Adjuvant CAPOX can be safely administered to Japanese patients with stage II/III colon cancer.
\end{abstract}

Colorectal cancer is the leading cause of cancer death among women and the third-highest cause of cancer death among men in Japan (1). A previous large-scale phase III study of stage II and III colon cancer (MOSAIC trial) demonstrated that fluorouracil (5-FU), leucovorin (LV) and oxaliplatin

Correspondence to: Mitsukuni Suenaga, Department of Gastroenterology, Cancer Institute Hospital, Japanese Foundation for Cancer Research, 3-8-31, Ariake, Koto-ku, Tokyo, Japan. Tel: +81 335200111, Fax: +81 335700343, e-mail: m.suenaga1972@gmail.com

Key Words: Early colon cancer, capecitabine, oxaliplatin, adjuvant therapy.
(FOLFOX4) improved 3-year disease-free survival (DFS) compared to 5-FU/LV alone: $78.2 \% v s .72 .9 \%$, hazard ratio $(\mathrm{HR})=0.77, p=0.002$ (2). In an updated analysis, the MOSAIC revealed significant improvement of 5-year DFS $(66.4 \%$ vs. $58.9 \%, \mathrm{HR}=0.78,95 \% \mathrm{CI}=0.65-0.93, p=0.005)$ and 6-year overall survival (OS) $(72.9 \%$ vs. 68.7\%, $\mathrm{HR}=0.80,95 \% \mathrm{CI}=0.65-0.097, p=0.023)$ in stage III patients and potential benefit in high-risk stage II colon cancer (5year DFS: $82.3 \%$ vs. $74.6 \% \mathrm{HR}=0.72,95 \% \mathrm{CI}=0.50-1.02$ ) (3). The National Surgical Adjuvant Breast and Bowel Project (NSABP)-07 also demonstrated significant improvement of 3-year DFS by adding oxaliplatin to weekly bolus 5-FU/LV (FLOX regimen) in patients with stage II or III colon cancer (4). An alternative oxaliplatin-based chemotherapy consisting of capecitabine and oxaliplatin (CAPOX regimen) was investigated in adjuvant setting for stage III colon cancer (NO16968 trial), and 3-year DFS was significantly improved compared to bolus 5-FU/LV (70.9\% vs. $66.5 \%, \mathrm{HR}=0.80,95 \% \mathrm{CI}=0.69-0.93, p=0.0045)$. A similar trend was shown in 5-year OS (77.6\% vs. $74.2 \%$, $\mathrm{HR}=0.87,95 \% \mathrm{CI}=0.72-1.05, p=0.1486)(5)$. In the final results of the NO16968 trial after long-term follow-up, 7year DFS were $63 \%$ and $56 \%(\mathrm{HR}=0.80,95 \% \mathrm{CI}=0.69-0.93$, $p=0.004)$, and 7 -year OS rates were $73 \%$ and $67 \%$ (HR=0.83, 95\% CI $=0.70-0.99, p=0.04)$ (6). Currently, FOLFOX and CAPOX are considered the most effective worldwide adjuvant treatments for stage III colon cancer (7, 8). In Japan, CAPOX was approved in adjuvant setting following the results from the NO16968 trial, though its feasibility in Japanese patients had not been confirmed at approval. To our knowledge, there have been no reports about prospective trials of adjuvant CAPOX treatment for Japanese patients with stage III colon cancer. Accordingly, we performed a feasibility study (ACTOR) to evaluate the 
safety, treatment completion or compliance of adjuvant CAPOX in Japanese patients with stage II/III colon cancer at a single institute in Japan.

\section{Patients and Methods}

Study design and end-points. The ACTOR study was a prospective, single-arm, open-label feasibility study performed at a single center in Japan. We evaluated the safety and efficacy of adjuvant CAPOX in stage II/III colon cancer patients. This study was performed in accordance with the Declaration of Helsinki and the ethical guidelines for clinical studies. The institutional review board at the Cancer Institute Hospital of the Japanese Foundation of Cancer Research approved the protocol and the study is registered with the University Hospital Medical Information Network Clinical Trials Registry (ID 000008029).

The primary end-point was the completion rate of treatment after 8 cycles of adjuvant CAPOX, while the secondary endpoints were the completion rate of oxaliplatin, DFS, relapse-free survival (RFS), and OS, adverse effect, correlation of relative dose intensity (RDI) with prognosis, and correlation of stage with prognosis. On the basis of a previous clinical trial (NO16968) that demonstrated a completion rate of adjuvant CAPOX of $69 \%$ in stage III colon cancer patients and other trials that showed those of $74.7 \%-81.8 \%$ though the evaluated treatment was FOLFOX, not CAPOX, we assumed the expected completion rate of treatment would be $75 \%$. Thirty-three patients were estimated to make the width of the $95 \%$ confidence interval (CI) of the completion rate of treatment about $30 \%$ with a range from $60 \%$ to $90 \%$. The target number of patients was therefore set at 36 to take into account those who would be excluded from the analysis set. The expected enrollment period was 1 year, and an additional follow-up was provided 3 years from the last patient's enrolment.

Patients. Eligible patients had a histologically confirmed diagnosis of stage II/III colon cancer and received surgical resection with D2 or greater lymphadenectomy confirmed as curative resection (curative level A) with no pathologically residual tumors. They also met the following criteria: age 20 years or older; Eastern Cooperative Oncology Group (ECOG) performance status 0-1; no history of prior chemotherapy or radiation therapy; neutrophil count $\geq 2,500 / \mathrm{mm}^{3}$; platelet count $\geq 100,000 / \mathrm{mm}^{3}$; hemoglobin $\geq 9.0 \mathrm{~g} / \mathrm{dl}$; total bilirubin $\leq 2.0$ times the upper limit of normal; aspartate aminotransferase and alanine aminotransferase $\leq 2.5$ times the upper limit of normal; and signed informed consent. Patients with any of the following conditions were excluded: severe peripheral sensory neuropathy (PSN); a history of serious hypersensitivity to drugs; active infection; interstitial lung disease, severe emphysema, or pulmonary fibrosis; paralytic or mechanical bowel obstruction; uncontrolled hypertension; uncontrolled diabetes; cirrhosis; clinically significant cardiovascular disease; history of myocardial infarction within the previous 3 months; uncontrolled angina pectoris or arrhythmia; multiple primary cancers within the past 5 years; pleural effusion requiring drainage ascites or pericardial effusion; uncontrolled diarrhea; clinically significant mental or psychological disease; and any other condition making a patient unsuitable for this study. Adverse effects were graded according to Common Terminology Criteria for Adverse Events version 4.0 in all patients every 3 weeks or less, or before each treatment cycle.
Protocol treatment. The CAPOX regimen was administered every 3 weeks with a total of eight cycles. On day 1 , oxaliplatin $\left(130 \mathrm{mg} / \mathrm{m}^{2}\right)$ was given as a 2-hour intravenous infusion and capecitabine 1,000 $\mathrm{mg} / \mathrm{m}^{2}$ given twice daily from evening of day 1 to morning of day 15 . The study treatment was delayed if any of the following criteria were not met on the scheduled day of administration or the previous day: a neutrophil count $\geq 1,500 / \mathrm{mm}^{3}$, a platelet count $\geq 75,000 / \mathrm{mm}^{3}$, diarrhea $\leq$ grade 1 , stomatitis $\leq$ grade 1 , and hand-foot syndrome (HFS) $\leq$ grade 1. The oxaliplatin dose was reduced to 100 or $85 \mathrm{mg} / \mathrm{m}^{2}$ if grade $3 \leq$ neutropenia or thrombocytopenia, PSN with pain or dysfunction or persistent PSN, or any grade $3 \leq$ non-hematological toxicities occurred. Capecitabine was reduced to 750 or $500 \mathrm{mg} / \mathrm{m}^{2}$ if persistent grade $3 \leq$ neutropenia, thrombocytopenia, grade $2 \leq$ diarrhea, grade $2 \leq$ stomatitis, or grade $2 \leq$ HFS occurred.

The study was terminated if any of the following adverse events continued after a 28 -day washout period: grade $3 \leq$ neutropenia or thrombocytopenia, grade $2 \leq$ diarrhea, grade $2 \leq$ stomatitis, or grade $2 \leq$ HFS. Oxaliplatin was discontinued if persistent PSN with pain or dysfunction over 21 days. Both oxaliplatin and capecitabine were discontinued if a grade $3 \leq$ allergic reaction occurred.

Statistical analysis. The completion rate of adjuvant CAPOX as primary endpoint was defined as a proportion of number of administered treatment cycles to 8 cycles; and the completion rate of oxaliplatin was also defined similarly. The RDI was calculated for total treatment cycles for individuals as follows: (administered dose/planned dose $) \times(21 /$ actual treatment days $) \times 100(\%)$. DFS was defined as the time between the date of registration for the study and the date of confirming relapse, secondary cancer or death from any cause; data on patients without death were censored on the date at which the patient was last confirmed to be alive. RFS was defined as the time between the date of registration and the date of confirming relapse or death; data on patients without relapse were censored at the time the patient was last confirmed to be alive. OS was calculated from the date of registration until the date of death from any cause. In patients who were lost to follow-up, data were censored on the date the patient was last confirmed to be alive. DFS, RFS, and OS were estimated by the Kaplan-Meier method and compared using the log-rank test; predictive or prognostic factors were identified by univariate analysis. Analysis of clinical outcomes by RDI was planned, comparing patients with RDI $\geq 80 \%$ to those with RDI $<80 \%$. All analyses were carried out using Statistical Package for the Social Sciences software version 22.0 (IBM Corporation, Armonk, NY, USA). $p$-Value $<0.05$ was considered to indicate statistical significance.

\section{Results}

Baseline demographics and clinical characteristics. Thirtysix patients were enrolled in this study between June 2012 and July 2013. All patients were eligible for safety and efficacy. The median follow-up time was 51.5 months (range=20.8-63.8 months). The baseline characteristics of the enrolled patients are summarized in Table I. The median age was 62.5 years (range $=30-73$ years) and two patients were over 70 years old $(5.6 \%)$.

Treatment. Details of treatment in 36 patients are summarized in Table II. Median cycles of adjuvant CAPOX 
Table I. Baseline demographic and clinical characteristics of patients $(N=36)$.

\begin{tabular}{|c|c|c|}
\hline Characteristics & $\mathrm{N}$ & $\%$ \\
\hline \multicolumn{3}{|l|}{ Gender } \\
\hline Male & 13 & 36.1 \\
\hline Female & 23 & 63.9 \\
\hline \multicolumn{3}{|l|}{ Age (years) } \\
\hline Median (range) & $62.5(30-73)$ & \\
\hline \multicolumn{3}{|l|}{ ECOG Performance status } \\
\hline 0 & 36 & 100 \\
\hline 1 & 0 & 0 \\
\hline \multicolumn{3}{|l|}{ Primary tumor site } \\
\hline Colon & 23 & 63.9 \\
\hline Rectum (Rs) & 13 & 36.1 \\
\hline \multicolumn{3}{|l|}{ Primary tumor sidedness } \\
\hline Right-sided & 24 & 66.7 \\
\hline Left-sided & 12 & 33.3 \\
\hline \multicolumn{3}{|l|}{ Pathological Stage } \\
\hline II & 7 & 19.4 \\
\hline III & 29 & 80.6 \\
\hline \multicolumn{3}{|l|}{ Histology } \\
\hline Well differentiated & 8 & 22.2 \\
\hline Moderately differentiated & 25 & 69.4 \\
\hline Poorly differentiated & 3 & 8.3 \\
\hline \multicolumn{3}{|l|}{ Pathological T stage } \\
\hline $\mathrm{T} 1$ & 3 & 8.3 \\
\hline $\mathrm{T} 2$ & 4 & 11.1 \\
\hline $\mathrm{T} 3$ & 14 & 38.9 \\
\hline $\mathrm{T} 4 \mathrm{a}$ & 13 & 36.1 \\
\hline $\mathrm{T} 4 \mathrm{~b}$ & 2 & 5.6 \\
\hline \multicolumn{3}{|l|}{ Pathological N stage } \\
\hline No & 7 & 19.4 \\
\hline $\mathrm{N} 1$ & 20 & 55.6 \\
\hline $\mathrm{N} 2$ & 9 & 22.2 \\
\hline
\end{tabular}

and oxaliplatin were both 8 cycles (range $=1-8$ cycles). Median total dosage of oxaliplatin and capecitabine were $890 \mathrm{mg} / \mathrm{m}^{2}$ (range $=130-1040 \mathrm{mg} / \mathrm{m}^{2}$ ) and $294,000 \mathrm{mg} /$ body (range $=3,000-403,200 \mathrm{mg} /$ body). Median RDI of oxaliplatin and capecitabine were $75.6 \%$ (range=53.8-100\%) and $80.0 \%$ (range $=7.1-100 \%)$. Dose modifications for oxaliplatin and capecitabine were required in 18 patients $(50.0 \%)$ and 12 patients $(33.3 \%)$ owing to mainly hematological toxicities followed by gastrointestinal adverse effects. Treatment was delayed in 30 patients $(83.3 \%)$ by mainly hematological toxicities $(69.6 \%)$ followed by gastrointestinal events. Treatment was terminated in 8 patients $(22.2 \%)$. Three patients $(5.6 \%)$ refused continuing treatment, and 2 patients $(5.6 \%)$ stopped treatment because of thrombocytopenia and severe skin toxicity. Oxaliplatin was removed in 6 patients $(16.7 \%)$ who completed 8 treatment cycles owing to PSN in $4(11.1 \%)$ and personal reason in 2 patients $(5.6 \%)$.
Table II. Details of treatment.

\begin{tabular}{lc}
\hline Treatment & $\mathrm{N}=36$ \\
\hline Median duration between surgery & \\
and chemotherapy (range) & $00(37-56)$ days \\
Median cycles of CAPOX (range) & $8(1-8)$ \\
Median cycles of oxaliplatin (range) & $8(1-8)$ \\
Treatment delay (\%) & $30(83.3)$ \\
Median total dosage of & \\
oxaliplatin (range) & $(130-1040) \mathrm{mg} / \mathrm{m}^{2}$ \\
Median total dosage of & \\
capecitabine (range) & $75.6 \%(53.8-100)$ \\
Median RDI of oxaliplatin (range) & $80.0 \%(7.1-100)$ \\
Median RDI of capecitabine (range) & $18(50.0)$ \\
Dose reduction, (\%) & $18(50.0)$ \\
Oxaliplatin, (\%) & $12(33.3)$ \\
Capecitabine, $(\%)$ & \\
Reason for dose reduction & $10(27.8)$ \\
Hematological & $5(13.9)$ \\
Gastrointestinal & $2(5.6)$ \\
Peripheral sensory neuropathy & $1(2.8)$ \\
Hand-foot syndrome & $1(2.8)$ \\
Liver dysfunction & $30(83.3)$ \\
Treatment delay (\%) & \\
Reason for delay & $25(69.6)$ \\
Hematological & $4(11.1)$ \\
Gastrointestinal & $1(2.8)$ \\
Peripheral sensory neuropathy & $1(2.8)$ \\
Hand-foot syndrome & $2(5.6)$ \\
Liver dysfunction & $25(69.6)$ \\
Hematological & \\
\hline &
\end{tabular}

RDI, Relative dose intensity.

Primary end-point. The completion rate for adjuvant CAPOX was $77.8 \%(95 \% \mathrm{CI}=63.5-92.0)$, and the primary end-point was met. A total of $80.6 \%$ of the patients received seven or more cycles of CAPOX.

Secondary end-points. The completion rate of oxaliplatin was $61.1 \%(95 \% \mathrm{CI}=44.4-77.8)$, and $80.6 \%$ of the patients received six or more administrations of the medication. Three-year DFS was $83.3 \%$ (8 events) in all patients and one patient had secondary cancer 52.7 months from the registration. Median DFS was not reached. Three-year DFS in stage II and III patients were $100 \%$ and $79.3 \%$, respectively (log-rank, $p=0.136$ ). Association between clinicopathological variables and outcomes was summarized in Table III. In stage III patients, right-sided tumor and T4 were significantly associated with shorter DFS than left-sided tumor and T1-3 (log-rank, $p=0.026 ;$ log-rank, $p=0.014$ ). In addition, we defined $\mathrm{T} 1-3 / \mathrm{N} 1$ as low risk, and $\mathrm{T} 4$ or N2 as high risk in accordance with recent report (9). The combination risk was significantly associated with DFS (low risk $v s$. high risk, logrank, $p=0.021$ ). No significant difference was observed in RDI 
Table III. Association between baseline characteristics and outcomes in stage III ( $N=29)$.

\begin{tabular}{|c|c|c|c|c|c|c|c|c|c|}
\hline \multirow[t]{2}{*}{ Variables } & \multicolumn{3}{|c|}{ 3-year DFS } & \multicolumn{3}{|c|}{ 3-year RFS } & \multicolumn{3}{|c|}{ 3-year OS } \\
\hline & $\%$ & $\mathrm{~N}$ of events & $p$-Value* & $\%$ & $\mathrm{~N}$ of events & $p$-Value* & $\%$ & $\mathrm{~N}$ of events & $p$-Value* \\
\hline Male $(n=10)$ & 90.0 & 2 & 0.344 & 90.0 & 1 & 0.205 & 100.0 & 0 & 0.311 \\
\hline Female $(\mathrm{n}=19)$ & 73.7 & 6 & & 73.7 & 6 & & 94.7 & 2 & \\
\hline Right-sided $(\mathrm{n}=19)$ & 68.4 & 8 & 0.026 & 68.4 & 7 & 0.035 & 94.7 & 2 & 0.291 \\
\hline Left-sided $(n=10)$ & 100.0 & 0 & & 100.0 & 0 & & 100.0 & 0 & \\
\hline T1-3 $(n=18)$ & 94.4 & 2 & 0.014 & 94.4 & 1 & 0.003 & 100.0 & 0 & 0.057 \\
\hline $\mathrm{T} 4(\mathrm{n}=11)$ & 54.5 & 6 & & 54.5 & 6 & & 90.9 & 2 & \\
\hline $\mathrm{N} 1(\mathrm{n}=20)$ & 90.0 & 4 & 0.143 & 90.0 & 3 & 0.082 & 100.0 & 0 & 0.025 \\
\hline $\mathrm{N} 2(\mathrm{n}=9)$ & 55.6 & 4 & & 55.6 & 4 & & 88.9 & 2 & \\
\hline Low risk $(n=14)$ & 100.0 & 1 & 0.021 & 100.0 & 0 & 0.004 & 100.0 & 0 & 0.157 \\
\hline High risk $(\mathrm{n}=15)$ & 60.0 & 7 & & 60.0 & 7 & & 93.3 & 2 & \\
\hline RDI of oxaliplatin $<0.8(n=16)$ & 81.3 & 5 & 0.669 & 81.3 & 4 & 0.906 & 93.8 & 1 & 0.879 \\
\hline RDI of oxaliplatin $\geq 0.8 \quad(n=13)$ & 76.9 & 3 & & 76.9 & 3 & & 100.0 & 1 & \\
\hline RDI of capecitabine $<0.8(n=14)$ & 78.6 & 5 & 0.435 & 78.6 & 4 & 0.619 & 92.9 & 1 & 0.918 \\
\hline RDI of capecitabine $\geq 0.8 \quad(n=15)$ & 80.0 & 3 & & 80.0 & 3 & & 100.0 & 1 & \\
\hline
\end{tabular}

DFS: Disease-free survival; RFS: relapse-free survival; OS: overall survival; RDI: relative dose intensity. ${ }^{*}$-Value was based on log-rank test in the univariate analysis. All events were counted at the data cut-off point.

Table IV. Clinical significance of risk classification depending on tumor location in stage III.

\begin{tabular}{|c|c|c|c|c|c|c|c|c|c|}
\hline \multirow[t]{2}{*}{ Tumor location and risk } & \multicolumn{3}{|c|}{ 3-year DFS } & \multicolumn{3}{|c|}{ 3-year RFS } & \multicolumn{3}{|c|}{ 3-year OS } \\
\hline & $\%$ & $\mathrm{~N}$ of events & $p$-Value* & $\%$ & $\mathrm{~N}$ of events & $p$-Value* & $\%$ & $\mathrm{~N}$ of events & $p$-Value* \\
\hline \multicolumn{10}{|l|}{ Right-sided } \\
\hline Low risk $(n=6)$ & 100.0 & 1 & 0.142 & 100.0 & 0 & 0.037 & 100.0 & 0 & 0.316 \\
\hline High risk $(\mathrm{n}=13)$ & 53.8 & 7 & & 53.8 & 7 & & 92.3 & 2 & \\
\hline \multicolumn{10}{|l|}{ Left-sided } \\
\hline Low risk $(\mathrm{n}=8)$ & 100.0 & 0 & N.A & 100.0 & 0 & N.A & 100.0 & 0 & N.A \\
\hline High risk $(n=2)$ & 100.0 & 0 & & 100.0 & 0 & & 100.0 & 0 & \\
\hline
\end{tabular}

DFS: Disease-free survival; RFS: relapse-free survival; OS: overall survival; RDI: relative dose intensity; N.A: not applicable. ${ }^{*} p$-Value was based on log-rank test in the univariate analysis. All events were counted at the data cut-off point.

of either oxaliplatin or capecitabine. Three-year RFS was $83.3 \%$ and median RFS was not reached for all patients at the point of analysis. Three-year RFS in stage II and III patients were $100 \%$ and $79.3 \%$. In stage III patients, right-sided tumor and T4 were significantly associated with shorter RFS than left-sided tumor and T1-3 (log-rank, $p=0.035$; log-rank, $p=0.003)$. N stage correlated with RFS, but was not statistically significant. A significant difference was observed in combination risk (low risk $v s$. high risk, log-rank, $p=0.004$ ). No significant difference was observed in RDI of any drugs. 3 -year OS was $97.2 \%$ and median OS was not reached in all population and subgroups based on stage. Patients with T4 or N2 had shorter OS than those with T1-3 or N1 (log-rank, $p=0.057$; log-rank, $p=0.025$ ).
Clinical significance of risk classification depending on tumor location. In right-sided tumor, high-risk patients had poor 3-year DFS and 3-year RFS compared with low-risk patients $(53.8 \%$ vs. $100 \%, p=0.142 ; 53.8 \%$ vs. $100 \%$, $p=0.037$ ); meanwhile there was no difference among different risk groups in left-sided tumor (Table IV).

Safety. Adverse events for 36 patients are summarized in Table V. The most common grade $\geq 3$ hematological adverse events were neutropenia $(16.7 \%)$ and thrombocytopenia (8.3\%). In non-hematological grade $\geq 3$ adverse events, gastrointestinal toxicities were the most frequent. PSN occurred in all patients and one patient experienced grade 3 event $(2.8 \%)$. Liver dysfunction was relatively highly 
Table V. Adverse events according to CTCAE version $4.0(N=36)$.

\begin{tabular}{|c|c|c|c|c|c|c|}
\hline \multirow[t]{2}{*}{ Adverse events } & \multicolumn{6}{|c|}{$\mathrm{n}(\%)$} \\
\hline & Grade 1 & Grade 2 & Grade 3 & Grade 4 & All Grade & Grade $\geq 3$ \\
\hline \multicolumn{7}{|l|}{ Hematological: } \\
\hline Leukopenia & $20(55.6)$ & 7 (19.4) & 0 & 0 & $27(75.0)$ & 0 \\
\hline Neutropenia & $1(2.8)$ & $14(38.9)$ & $6(16.7)$ & 0 & $21(58.3)$ & $6(16.7)$ \\
\hline Anemia & $14(38.9)$ & $3(8.3)$ & 0 & 0 & $17(47.2)$ & 0 \\
\hline Thrombocytopenia & $13(36.1)$ & $10(27.8)$ & $2(5.6)$ & $1(2.8)$ & $26(72.2)$ & $3(8.3)$ \\
\hline Febrile neutropenia & - & - & 0 & 0 & 0 & 0 \\
\hline \multicolumn{7}{|l|}{ Non-hematological: } \\
\hline Diarrhea & $15(41.7)$ & $6(16.7)$ & $1(2.8)$ & 0 & $22(61.1)$ & $1(2.8)$ \\
\hline Constipation & $12(33.3)$ & $6(16.7)$ & 0 & 0 & $18(50.0)$ & 0 \\
\hline Anorexia & $12(33.3)$ & $4(11.1)$ & $3(8.3)$ & 0 & $19(52.8)$ & $3(8.3)$ \\
\hline Nausea & $11(30.6)$ & $9(25.0)$ & $5(13.9)$ & 0 & $25(69.4)$ & $5(13.9)$ \\
\hline Vomiting & $8(22.2)$ & $1(2.8)$ & $1(2.8)$ & 0 & $10(27.8)$ & $1(2.8)$ \\
\hline Stomatitis & $9(25.0)$ & $1(2.8)$ & 0 & 0 & $10(27.8)$ & 0 \\
\hline Fatigue & 0 & $1(2.8)$ & 0 & 0 & $1(2.8)$ & 0 \\
\hline Hand-foot syndrome & $27(75.0)$ & $1(2.8)$ & $1(2.8)$ & 0 & $29(80.1)$ & $1(2.8)$ \\
\hline Muco-cutaneo-ocular syndrome & 0 & 0 & $1(2.8)$ & 0 & $1(2.8)$ & $1(2.8)$ \\
\hline Peripheral sensory neuropathy & $30(83.3)$ & $5(13.9)$ & $1(2.8)$ & 0 & $36(100.0)$ & $1(2.8)$ \\
\hline Allergic reaction & $1(2.8)$ & 0 & 0 & 0 & $1(2.8)$ & 0 \\
\hline Total bilirubin increased & $16(44.4)$ & $4(11.1)$ & 0 & 0 & $20(55.6)$ & 0 \\
\hline AST increased & $30(83.3)$ & $2(5.6)$ & $1(2.8)$ & 0 & $33(91.7)$ & $1(2.8)$ \\
\hline ALT increased & $24(66.7)$ & 0 & $2(5.6)$ & 0 & $26(72.2)$ & $2(5.6)$ \\
\hline
\end{tabular}

AST: Aspartate aminotransferase; ALT: alanine aminotransferase.

observed, though severe episodes were not remarkable. There were no other severe treatment-related adverse events and no treatment-related deaths during treatment.

\section{Discussion}

We herein report the first evidence from a clinical trial that investigated the safety and efficacy of adjuvant CAPOX in Japanese patients with stage II/III colon cancer. The completion rate of adjuvant CAPOX $(77.8 \%)$ was superior to the expected completion rate $(75 \%)$; and based on the results that approximately $81 \%$ of the patients completed 6 cycles of oxaliplatin and PSN accounted for $28.6 \%(4 / 14)$ of reasons for oxaliplatin discontinuation, PSN did not seem to be the most critical factor influencing treatment completion. In addition, the median RDIs of capecitabine and oxaliplatin in our study were comparable to those in NO16968 (80\% vs. 78\%; 76\% vs. 84\%) (5). According to the safety profile and dose modification including dose reduction and treatment delay in our study, prophylactic and appropriate use of antiemetic agents are recommended for treatment completion. Capecitabine-related HFS was manageable for diminishing severe events leading to adequate adherence to capecitabine, albeit the frequency of any grade event was high, as expected. FOLFOX is also an alternative choice of adjuvant therapy in stage III colon cancer in Japan, and a recent study (JFMC41-1001-C2; JOIN trial) demonstrated the tolerability of adjuvant mFOLFOX6 in Japanese patients with stage II or III colon cancer (10). In the study, the incidence of any grade PSN and grade $\geq 3$ were $83.8 \%$ and $5.8 \%$, and the median RDI of oxaliplatin was $78.2 \%$. The treatment completion rate was $67.0 \%$. Taken into consideration our study and the JOIN trial, both CAPOX and FOLFOX can be safely administered to Japanese patients.

Nevertheless, severe PSN has been recognized as the most critical side effect in adjuvant oxaliplatin-based chemotherapy, and the time-to-resolution for PSN after completion of adjuvant therapy has been shown to be up to several years $(3,11)$. Hence, in terms of avoiding severe cumulative PSN, optimum treatment cycles of oxaliplatin in adjuvant CAPOX and FOLFOX therapies have been discussed with regard to whether duration of treatment could be shortened without diminishing the efficacy. However, little has been reported on the association between efficacy and duration of oxaliplatin-based adjuvant chemotherapy. Our study protocol preplanned to compare the patients with RDI $\geq 80 \%$ to those with RDI $<80 \%$ for clinical outcomes: and no statistically significant difference was shown in DFS, RFS and OS, though the sample size was small. 
In 2017, the International Duration Evaluation of Adjuvant Chemotherapy (IDEA) Collaboration reported the first evidence of prospective pooled analysis of six phase III Trials Investigating duration of adjuvant Oxaliplatin-based therapy (3 vs. 6 months) for Patients with Stage III Colon Cancer $(\mathrm{N}=12,834)$, i.e. SCOT (UK, Denmark, Spain, Australia, Sweden, New Zealand), TOSCA (Italy), IDEA France, Alliance/SWOG 80702 (US, Canada), ACHIEVE (Japan) and HORG (Greece) $(9,12-14)$. The study design was based on the idea that shorter duration of oxaliplatin without loss of efficacy would be of benefit to patients evading cumulative dosedependent neurotoxicity. A non-inferiority margin of 3-month $v s$. 6-month was determined by following statistical assumptions: a maximal $12 \%$ increase in the risk of DFS events was considered acceptable to reduce cumulative toxicities by using a shorter duration of therapy (non-inferiority margin: $H R=1.12$ ). Although the 3-month arm experienced obviously fewer adverse events including neurotoxicity with a higher treatment completion and compliance rate compared with the 6-months arm, non-inferiority of 3-month compared with 6-month treatment was not met $(\mathrm{HR}=1.07,95 \% \mathrm{CI}=1.00$ 1.15). According to preplanned prognostic analysis, TNM stage ( T and $\mathrm{N}$ ) was not significantly associated with DFS difference between the groups. However, a post-hoc analysis for DFS showed non-inferiority in patients with low risk (T1-3 and N1), while high risk (T4 or N2) was unfavorable to the 3-month arm $((\mathrm{HR}=1.01,95 \% \mathrm{CI}=0.90-1.12 ; \mathrm{HR}=1.12,95 \% \mathrm{CI}=1.03-1.23)$. There was no significant interaction between treatment arm and risk for DFS (interaction $p$-value=0.11). Another pre-planned analysis by treatment regimen (CAPOX or FOLFOX) demonstrated non-inferiority in only patients receiving CAPOX ( $\mathrm{HR}=0.95,95 \% \mathrm{CI}=0.85-1.06)$ but not FOLFOX $(\mathrm{HR}=1.16$, $95 \% \mathrm{CI}=1.06-1.26)$. Significant interaction between treatment arm and regimen was observed for DFS (interaction $p$-value $=0.0051)$. Furthermore, combined analysis of risk and regimen showed that low-risk patients receiving CAPOX could benefit from 3-month treatment. Although the non-inferiority was not revealed within modified ITT population, the IDEA group proposed a consensus along with indicating the fact that the difference was not large between two different arms: 3month treatment is recommended in low-risk patients and could be an option in high-risk patients, and duration of treatment should be determined by tolerability of therapy, patient preference, assessment of risk of recurrence and choice of regimen after the initial 3-month treatment. Intriguingly, our data showed the risk classification (low or high risk) available only in right-sided colon cancer, though the subpopulation was small in number. Tumor location is well-known prognostic factor in stage III colon cancer and is suggested to be included in treatment plans in adjuvant therapy in addition to the abovementioned factors. A recent study investigated the relationship between tumor site (right- or left-sided) and outcomes using the Surveillance, Epidemiology, and End
Results Program (SEER) database, and demonstrated that rightsided tumor was associated with lower mortality in stage II, and higher mortality in stage III (15). However, survival benefit from chemotherapy was only for stage III disease regardless of tumor location; meanwhile, no benefit was observed for stage II patients for any tumor sides (16).

Taken together, adjuvant CAPOX regimen may be an allaround treatment option regardless of stage, combined risk, safety and duration; however, its superiority to FOLFOX still remains unclear because the IDEA was not originally designed to compare DFS between regimens (9). Further subgroup analysis among six IDEA groups is warranted to explore this issue. The limitations of our study include its small sample size to identify prognostic markers, and mixed population of stage II and III; hence, we performed prognostic analysis for stage III colon cancer patients. Furthermore, we showed the first clinical trial-based evidence of feasibility of adjuvant CAPOX in Japanese patients with stage II and III colon cancer.

In conclusion, adjuvant CAPOX was demonstrated to be feasible in Japanese patients with stage II/III colon cancer. Furthermore, primary tumor location with $\mathrm{T} / \mathrm{N}$ stage might confer individualized adjuvant oxaliplatin-based treatment.

\section{Conflicts of Interest}

The Authors declare that they have no conflicts of interest.

\section{Acknowledgments}

The Authors would like to thank the participating patients, their family members, and all researchers in this study. The Authors are grateful to Drs. Hiroyuki Uetake and Atsushi Sato for their support as independent review committee members and to Yuki Horiike and Chizuru Suizu for collecting the data.

\section{References}

1 Center for Cancer Control and Information Services, National Cancer Center. Cancer Statistics in Japan; 2014. Available from: http://ganjoho.jp/reg_stat/statistics/stat/summary.html. Accessed June 29, 2017.

2 André T, Boni C, Mounedji-Boudiaf L, Navarro M, Tabernero J, Hickish T, Topham C, Zaninelli M, Clingan P, Bridgewater J, Tabah-Fisch I and de Gramont A: Oxaliplatin, fluorouracil, and leucovorin as adjuvant treatment for colon cancer. N Engl J Med 350: 2343-2351, 2004.

3 André T, Boni C, Navarro M, Tabernero J, Hickish T, Topham C, Bonetti A, Clingan P, Bridgewater J, Rivera F and de Gramont A: Improved overall survival with oxaliplatin, fluorouracil, and leucovorin as adjuvant treatment in stage II or III colon cancer in the MOSAIC trial. J Clin Oncol 27: 3109-3116, 2009.

4 Kuebler JP, Wieand HS, O'Connell MJ, Smith RE, Colangelo LH, Yothers G, Petrelli NJ, Findlay MP, Seay TE, Atkins JN, Zapas JL, Goodwin JW, Fehrenbacher L, Ramanathan RK, Conley BA, Flynn PJ, Soori G, Colman LK, Levine EA, Lanier 
KS and Wolmark N: Oxaliplatin combined with weekly bolus fluorouracil and leucovorin as surgical adjuvant chemotherapy for stage II and III colon cancer: results from NSABP C-07. J Clin Oncol 25: 2198-2204, 2007.

5 Haller DG, Tabernero J, Maroun J, de Braud F, Price T, Van Cutsem E, Hill M, Gilberg F, Rittweger K and Schmoll HJ: Capecitabine plus oxaliplatin compared with fluorouracil and folinic acid as adjuvant therapy for stage III colon cancer. J Clin Oncol 29: 1465-1471, 2011

6 Schmoll HJ, Tabernero J, Maroun J, de Braud F, Price T, Van Cutsem E, Hill M, Hoersch S, Rittweger K and Haller DG: Capecitabine plus oxaliplatin compared with fluorouracil/folinic acid as adjuvant therapy for stage III colon cancer: Final results of the NO16968 randomized controlled phase III Trial. J Clin Oncol 33: 3733-3740, 2015.

7 Watanabe T, Itabashi M, Shimada Y, Tanaka S, Ito Y, Ajioka Y, Hamaguchi T, Hyodo I, Igarashi M, Ishida $H$, Ishiguro $M$, Kanemitsu Y, Kokudo N, Muro K, Ochiai A, Oguchi M, Ohkura Y, Saito Y, Sakai Y, Ueno H, Yoshino T, Fujimori T, Koinuma N, Morita T, Nishimura G, Sakata Y, Takahashi K, Takiuchi H, Tsuruta O, Yamaguchi T, Yoshida M, Yamaguchi N, Kotake K and Sugihara K: Japanese Society for Cancer of the Colon and Rectum (JSCCR) guidelines 2010 for the treatment of colorectal cancer. Int J Clin Oncol 17: 1-29, 2012.

8 NCCN Clinical Practice Guideline: Colon Cancer. ver. 2; 2017. Available from: https://www.nccn.org/professionals/physician gls/pdf/colon.pdf. Accessed June 29, 2017.

9 Shi Q, Sobrero AF, Shields AF, Yoshino T, Paul J, Taieb J, Sougklakos I, Kerr R, Labianca R, Meyerhardt JA, Bonnetain F, Watanabe T, Boukovinas I, Renfro LA, Grothey A, Niedzwiecki D, Torri V, Andre T, Sargent DJ and Iveson T: Prospective pooled analysis of six phase III trials investigating duration of adjuvant (adjuv) oxaliplatin-based therapy (3vs. 6 months) for patients (pts) with stage III colon cancer (CC): The IDEA (International Duration Evaluation of Adjuvant chemotherapy) collaboration. J Clin Oncol 35: abstr LBA1, 2017.

10 Kotaka M, Yoshino T, Oba K, Shinozaki K, Touyama T, Manaka $\mathrm{D}$, Matsui $\mathrm{T}$, Ishigure $\mathrm{K}$, Hasegawa $\mathrm{J}$, Inoue $\mathrm{K}$, Goto $\mathrm{K}$, Sakamoto J, Saji S, Ohtsu A and Watanabe T: Initial safety report on the tolerability of modified FOLFOX6 as adjuvant therapy in patients with curatively resected stage II or III colon cancer (JFMC41-1001-C2: JOIN trial). Cancer Chemother Pharmacol 76: 75-84, 2015.
11 Land SR, Kopec JA, Cecchini RS, Ganz PA, Wieand HS, Colangelo LH, Murphy K, Kuebler JP, Seay TE, Needles BM, Bearden JD 3rd, Colman LK, Lanier KS, Pajon ER Jr., Cella D, Smith RE, O'Connell MJ, Costantino JP and Wolmark N: Neurotoxicity from oxaliplatin combined with weekly bolus fluorouracil and leucovorin as surgical adjuvant chemotherapy for stage II and III colon cancer: NSABP C-07. J Clin Oncol 25: 2205-2211, 2007.

12 Sobrero AF, Lonardi S, Rosati G, Bartolomeo MD, Ronzoni M, Pella N, Scartozzi M, Banzi M, Zampino MG, Pasini F, Marchetti P, Cantore M, Zaniboni A, Rimassa L, Ciuffreda L, Ferrari D, Zagonel V, Maiello E, Rulli E and Labianca R: FOLFOX4/XELOX in stage II-III colon cancer: Efficacy results of the Italian three or six colon adjuvant (TOSCA) trial. J Clin Oncol 35: abstr 3501, 2017.

13 Iveson T, Kerr R, Saunders MP, Hollander NH, Tabernero J, Haydon AM, Glimelius B, Harkin A, Scudder C, Boyd K, Waterston AM, Medley LC, Wilson C, Ellis R, Essapen S, Dhadda AS, Harrison M, Falk S, Raouf S and Paul J: Final DFS results of the SCOT study: An international phase III randomised (1:1) non-inferiority trial comparing 3 versus 6 months of oxaliplatin based adjuvant chemotherapy for colorectal cancer. J Clin Oncol 35: abstr 3502, 2017.

14 Andre T, Bonnetain F, Mineur L, Bennouna J, Desrame J, Faroux R, Dauba J, Vernerey D, Aissat N, Louvet C, Lepère C, Dupuis OJM, Becouarn Y, Mabro M, Egreteau J, Bouche O, Deplanque G, Ychou M, Gramont AD and Taieb J: Oxaliplatinbased chemotherapy for patients with stage III colon cancer: Disease free survival results of the three versus six months adjuvant IDEA France Trial. J Clin Oncol 35: abstr 3500, 2017.

15 Weiss JM, Pfau PR, O'Connor ES, King J, LoConte N, Kennedy $\mathrm{G}$ and Smith MA: Mortality by stage for right- versus left-sided colon cancer: analysis of surveillance, epidemiology, and end results - Medicare data. J Clin Oncol 29: 4401-4409, 2011.

16 Weiss JM, Schumacher J, Allen GO, Neuman H, Lange EO, Loconte NK, Greenberg CC and Smith MA: Adjuvant chemotherapy for stage II right-sided and left-sided colon cancer: analysis of SEER-medicare data. Ann Surg Oncol 21: 1781-1791, 2014.

Received December 11, 2017

Revised December 23, 2017

Accepted December 29, 2017 